\title{
The Role of Internal Audit Unit in Fraud Prevention in Government Owned Hospitals in a Nigerian Setting
}

\author{
${ }^{1}$ Abu-Saeed Muslimat and ${ }^{2}$ Kabir Tahir Hamid \\ ${ }^{1}$ Department of Accounting, Kogi State Polytechnic, Lokoja. Nigeria \\ ${ }^{2}$ Department of Accounting, Bayero University, Kano. Nigeria
}

\begin{abstract}
A lot of attention has been given to the health sector both by the government and the private operators yet they seem not to meet expectation demanded of them particularly the government owned hospital due to excesses in financial administration. A weak internal control cannot provide sufficient accounting information to safeguard the assets and ensure effective and efficient operation. This study was therefore designed to assess the role of internal audit in fraud prevention in state government owned Hospitals in Kogi state of Nigeria. Four hypotheses were formulated in their null form as well as three research questions to guide the study. The study utilized the survey research design and data were generated through the questionnaire administered to the randomly selected respondents. Stratified random sampling was used. Data collected were analyzed using the non-parametric statistical tool that is the chi-square and the descriptive statistics. The SSPS version 15 was used in the computation of the data collected. The study revealed that the Internal Audit Unit of the hospitals are aware of their role to prevent fraud and are making a way forward by tracing and halting fraud but lack the basic knowledge needed to practically prevent fraud. It also revealed that there is cooperation between the audit staffs and staffs of other departments in provision of necessary documents although Chief Medical Directors (CMDs) strives to interfere in the operational activities of the internal audit unit. Therefore the role of the unit on fraud prevention is weak.
\end{abstract}

\section{Introduction}

A hospital is an institution where people receive medical, surgical, midwifery and nursing care. In other words, a hospital is an institution that coordinates the skills of doctors, nurses and support care personnel to provide health care services. There are two major components in all hospitals i.e. medical and administrative departments. The medical departments or units include; emergency room, surgical suites, intensive care unit (ICUs), pediatric and maternity wards and department of radiology, anesthesiology, pathology and rehabilitative medicine. While the administrative department consist of; account department, human resource department, internal audit department, medical records amongst others.

For an organization to be efficient and effective and be able to achieve its desired objectives, it needs to have amongst others good leadership, competent manpower, adequate resources and good measures of internal control. Connor (1979) said that internal control is considered important in an organization because today's economic environment requires that management of every organization either public or private should take adequate steps considered necessary to establish and sustain an effective internal control system with a view to ensuring effectiveness, efficiency and economical operations. It also ensures the accuracy and the completeness of accounting information as well as compliance with the rules and procedures. The system of internal control is seen as the integrated collection of control mechanisms used to achieve desired results, among which is the internal audit, which is an essential element of the internal control system.

Many organizations lack mechanisms for adequate monitoring of activities and operations, thereby not giving room for easy achievement of the business goals (Adeniji, 2004). Flaws and loopholes may still exist in an organization despite the existence of internal control system, which can easily be circumvented by individuals who are inclined towards fraudulent activities. Therefore measures have to be put in place to checkmate such fraudsters. One best way of curbing and/or minimizing the menace of fraud is through the institutionalization of a vibrant and effective internal audit unit.

The presence of an effective internal audit in an organization is not only to checkmate fraudsters, but also serves as a managerial control which functions by measuring and evaluating the effectiveness of other controls (Dandago, 2002). The primary function of the internal auditor is to evaluate processes that are in place to identify any weaknesses in internal controls that might lead to undetected fraud. When any such weaknesses are identified, they are reported to management for corrective action. The internal audit is expected to anticipate problems, visualize improvements and propose preventive actions (Effiok, 2003). The internal auditor has the responsibility to appraise the activities of other departments in an organization, and provides management with information that is useful in assessing operational effectiveness. 
This study therefore seeks to evaluate the impact of internal audit on fraud prevention in Kogi state hospitals, with a view to ascertain the impact of internal audit on fraud prevention in government owned hospitals.

\section{Materials And Method}

Survey research design was used for this study. The population of this study was made up of all the staff of audit, bursary and store units of all the state government owned hospitals in Kogi state of Nigeria which are eight in numbers. These hospitals are distributed in the three zone of the state. The western and the eastern zone each have three hospitals while the central zone has only two state owned hospitals. In addition to the units mentioned above, other units that are found in the various hospitals include the nursing units, pharmacy units, and works/service department, outpatient and inpatient units among others.

The research generated data from 84 respondents representing $45 \%$ of the population. This comprised of 22 staff of the internal audit, 34 from bursary and 28 from the stores. Stratified random sampling was utilized. The data for this study was collected through the use of questionnaires distributed among Account staff, Audit staff, and stores departments. Out of the 84 questionnaire distributed, only 72 were filled fully and returned. This accounted for about 86 percent of the sampled respondents. Data was analyzed using Statistical Package for Social Sciences (SPSS) version 15 and presented in form of mean, standard deviation and test for statistical significance using $95 \%$ confidence interval and chi square.

In line with the problem and the objectives of the study stated above, the following research questions were raised with a view to providing answers to them at the end of the study:

1. What is the role of internal audit unit in the prevention of fraud in Kogi state hospitals?

2. Do internal auditors in Kogi state hospitals acquaint themselves with the relevant audit standards relating to fraud prevention?

3. Are there any success recorded by the internal audit units of Kogi state hospitals vis-à-vis fraud prevention through mutual relationship between audit unit and other departments in the hospitals?

4. Is there any type of fraud prevented, detected and reported by internal audit unit to the management?

In order to achieve the objectives raised above, the following hypotheses were formulated in null form to guide the study:

$\mathbf{H}_{\mathbf{0 1}}$ There is no significant relationship between the role of internal audit and fraud prevention in Kogi state Hospitals.

$\mathbf{H}_{\mathbf{0 2}}$ There is no significant relationship between internal auditors' knowledge on relevant audit standards and fraud prevention in Kogi state Hospitals

$\mathbf{H}_{\mathbf{0 3}}$ Internal audits of Kogi state hospitals have not recorded any success on the issue of fraud prevention through mutual relationship between audit unit and other departments in the hospitals.

$\mathbf{H}_{\mathbf{0 4}}$ There is no type of fraud prevented, detected and reported by internal audit unit to the management.

III. Results And Discussion

Table 1: Summary of responses and test for significance on the role of internal audit unit and fraud prevention

\begin{tabular}{|l|l|l|l|l|l|}
\hline Roles Related to Internal Audit & Mean & SD & $\mathbf{X}^{\mathbf{2}}$ & $\mathbf{d f}$ & $\mathbf{p}$ value \\
\hline Internal audit prevents and detects fraud & 4.46 & 0.502 & 60.06 & 4 & 0.000 \\
\hline $\begin{array}{l}\text { Management ensure that all necessary measures } \\
\text { needed to prevent and detect fraud }\end{array}$ & 3.71 & 0.895 & 72.78 & 4 & 0.000 \\
\hline Procedures adopted are effective and efficient & 3.76 & 0.942 & 55.44 & 4 & 0.000 \\
\hline $\begin{array}{l}\text { There is independence and no interference by } \\
\text { management in its role of fraud prevention and } \\
\text { detection }\end{array}$ & 3.49 & 0.822 & 33.58 & 4 & 0.000 \\
\hline $\begin{array}{l}\text { Reports are proactive rather than reactive that } \\
\text { check financial and prevent fraud before } \\
\text { occurrence }\end{array}$ & & 1.40 & 33.42 & 4 & 0.000 \\
\hline
\end{tabular}

Table 1 above shows the responses as regards the role of internal audit unit in fraud prevention and detection. It also tests for statistical significance or these roles. The first role as mentioned in the table shows that on the average, the respondents agreed that internal audit prevents and detects fraud with a mean value of 4.46. This means that respondents are aware of the fact that among the functions of the internal audit department is to prevent and detect fraud. Also, it indicated that the respondents also agreed to the fact that management ensure that all necessary measures needed to prevent and detect fraud. This signifies that respondents feel that 
this is important for internal audit unit to function properly. In respect to the procedures adopted for efficiency and efficiency of internal audit, the mean value of 3.76 on the table shows that the respondents also agreed to this point on the average. Respondents were neutral on the average to these two points viz; that internal audit unit is independent in fraud prevention and detection and that their reports on fraud should be proactive rather than reactive. The mean values for these two points are 3.49 and 3.40 respectively. This indicates that respondents do not care if internal audit's report on fraud has tendency of minimizing and controlling the occurrence of fraud in the hospitals or not.

Table 1 also shows the result of test for significance of the role of audit unit in fraud prevention and detection using chi square test. The guide is that the null hypotheses is accepted if the p-value is greater than 0.05 and reject the null hypotheses if $\mathrm{p}$ - value is less than 0.05 .

Therefore, from the table it shows that internal audit actually prevents and detects fraud in the hospital $(p=0.000)$. The significance test also shows that management ensure that all necessary measures needed to prevent and detect fraud, procedures adopted are effective and efficient, there is independence and no interference by management in its role of fraud prevention and detection and that reports are proactive rather than reactive that check financial and prevent fraud before occurrence. All these had p-values far less than 0.05 , reason why the null hypotheses were rejected. This has further been confirmed by the results of the descriptive statistics obtained except for independence and no interference by management in its role of fraud prevention and detection where the mean value showed that respondents were neutral on that issue but the chi square test confirmed the statement.

Therefore, the overall result of the test for significance using the chi square method on the null hypothesis one $\left(\mathrm{H}_{01}\right)$ which states that there is no relationship between internal audit and fraud prevention in hospitals is rejected. Thus, it shows that there is a significant relationship between internal audit and fraud prevention in the hospitals. In other words, the study is accepting the alternative hypothesis. This finding is in line with a similar study by Thomas and Clement (2009) who concluded their study by reporting that the attitude of internal auditors are slightly more positive towards responsibilities for fraud prevention rather than fraud detection despite the fact that internal auditors are generally knowledgeable about professional standards. Welch, et al (1996) in similar studies said that organizations functioned more effectively in detecting fraud with the presence of internal audit when compared with those without.

The finding of this study also correlates with finding of KPMG study where they also found out that internal audit function was involved in detection of approximately 43 percent of reported frauds in 1998 while the external audit function was involved in detecting only 4 percent of the reported fraud (KPMG, 1999, 2003, 2006). Also, a study carried out in Australia by Birkett et al (1999) also showed that fraud detection was included in internal audit work while assisting the external auditor was being excluded.

It should be noted however that the studies of DeZoort and Harrison (2008) which revealed that management has the highest percentages of fraud detection responsibility, followed by internal accountants and internal auditors is in contrast with the findings of this study.

Table 2: Summary of responses and test for significance on the knowledge of internal auditors' knowledge on the relevant standard

\begin{tabular}{|l|l|l|l|l|l|}
\hline Standards & Mean & SD & $\mathbf{X}^{\mathbf{2}}$ & df & p value \\
\hline $\begin{array}{l}\text { Staffs fully aware of provisions by government and } \\
\text { laws relating to fraud prevention and detection }\end{array}$ & 4.08 & 0.835 & 1.00 & 4 & 0.607 \\
\hline $\begin{array}{l}\text { Integration of provisions of all the relevant audit acts } \\
\text { into audit procedures. }\end{array}$ & 4.08 & 0.622 & 25.75 & 4 & 0.000 \\
\hline $\begin{array}{l}\text { Effective execution of relevant acts help in detection } \\
\text { and prevention of fraud }\end{array}$ & 4.24 & 0.593 & 28.58 & 4 & 0.000 \\
\hline
\end{tabular}

Table 2 gives the descriptive statistics on the awareness on the relevant standards related to fraud detection and prevention; the respondents agreed that staffs are fully aware of the provisions by government and laws relating to fraud prevention and detection with an average value of 4.08. The average response on the integration of provisions of all the relevant audit acts into audit procedure also showed that they also agreed to this point (4.08). The internal audit also agreed on an average that integration of provisions of all the relevant audit acts into audit procedures be done in hospitals (mean value $=4.08$ ) and that effective execution of relevant acts help in detection and prevention of fraud (mean value $=4.08$ ).

The table also displays test for significance on the standards related to fraud detection and prevention using the chi square. According to this table, the null hypothesis is accepted by concluding that staffs are not fully aware of the provisions by government and laws relating to fraud prevention and detection $(\mathrm{p}=0.607)$. This result is not similar to that obtained from the same table which showed an average mean of 4.07. Integration of provisions of all the relevant audit acts into audit procedures and effective execution of relevant 
acts helping in detection and prevention of fraud are both statistically significant having obtained p-value of 0.000 for both.

Based on the a foregoing, the study is accepting the null hypothesis which states that internal auditors of hospitals in Kogi States Hospitals does not acquire relevant knowledge needed to prevent and or detect fraud. This finding negatively correlate that of Thomas and Clement (2009) who found out that internal auditor are generally knowledgeable about professional standards relating to fraud.

Table 3: Summary of responses and test for significance on the type of fraud prevented, detected and reported by internal audit unit to the management

\begin{tabular}{|l|l|l|l|l|l|}
\hline Instances of Fraud & Mean & SD & $\mathbf{X}^{\mathbf{2}}$ & df & p value \\
\hline Misappropriation of funds & 4.18 & 0.845 & 66.19 & 4 & 0.000 \\
\hline Falsification of funds & 3.99 & 0.911 & 39.81 & 4 & 0.000 \\
\hline $\begin{array}{l}\text { Submission of claims for goods and services not } \\
\text { supplied }\end{array}$ & 3.81 & 0.799 & 63.13 & 4 & 0.000 \\
\hline Over valuation of supplies & 3.86 & 0.893 & 41.89 & 4 & 0.000 \\
\hline Supply of sub-standard goods & 3.88 & 0.768 & 82.58 & 4 & 0.000 \\
\hline Falsification of medical records & 3.43 & 0.836 & 46.47 & 4 & 0.000 \\
\hline Unauthorized disposal of assets & 2.69 & 1.469 & 4.81 & 4 & 0.000 \\
\hline Salaries of ghost workers & 4.08 & 0.818 & 71.47 & 4 & 0.000 \\
\hline
\end{tabular}

Table 3 shows the type of fraud prevented and reported by internal audit unit to the management. From the table, a mean value of 4.18 shows that the respondents agreed on the average that misappropriation of funds is one of the frauds in the hospitals. Others to which respondents agreed on the average which include falsification of funds (mean value= 3.99); submission of claims for goods and services not supplied (mean value $=3.81$ ); over valuation of supplies (mean value $=3.86$ ); supply of substandard goods (mean value $=3.88$ ) and salaries of ghost workers (mean value $=4.08$ ). On the average, the respondents were indifferent on falsification of medical records and unauthorized disposal of assets as instances of fraud in the hospital with mean values of 3.43 and 2.69 respectively.

Table 3 also shows the chi square and p-values for types of fraud prevented, detected and reported by internal audit unit to the management according the respondents. The test for significance on the type of frauds managed by internal audit unit using the chi square method shows that the null hypotheses that unauthorized disposal of assets is not a type of fraud managed in the hospitals is accepted. The analysis revealed that the pvalue was greater than 0.05 . Other instances of fraud show that all other ones are statistically significant with $\mathrm{p}$ value of 0.000 for all which is less than the specified value of 0.05 .

This finding is in line with that obtained in the descriptive survey using mean except for falsification of medical record where the respondents' seemed indifferent in their responses. The findings also show that the internal audit units were able to detect frauds from various units like accounts and stores. Therefore from this, we could conclude by rejecting the third null hypothesis $\left(\mathrm{H}_{03}\right)$ which stated that internal audit units in hospital record no success in detecting frauds of any types since all the instance of fraud listed in the above table were all detected by the internal audit unit in the various hospitals.

The respondents' average response on the relationship between the CMD and internal audit unit as regards to fraud prevention is as shown on table 4. The table shows that the respondents agreed on the average that the CMD place all necessary measures to assist internal audit unit (mean value $=3.83$ ). It also showed that the respondents also agreed on the average to the fact that the reports made by the internal audit unit are taken serious and culprits are disciplined accordingly by the CMD (mean value=4.01). A mean response of 3.19 and 3.36 indicate that the respondents are of the opinion that internal audit unit are not interfered with by the CMD and that internal audit unit is independent of the CMD respectively.

The CMDs being the head of the various hospitals have a vital role to play on the success and role of internal audit. Negative interference of the CMD into the roles to be played by the internal audit unit may restrain them from carrying out their duties effectively. Negative interference may include dictating to the internal audit those duties to carry out and those not to. There are possibilities that the CMDs sometimes may want to curtail the duties of internal audit and may not take reports by them seriously due to personal and or selfish reasons. 
The Role Of Internal Audit Unit In Fraud Prevention In Government Owned Hospitals In A Nigerian Setting

Table 4: Summary of responses and test for significance on the relationship between the CMD and internal audit unit regarding fraud prevention

\begin{tabular}{|l|l|l|l|l|l|}
\hline Relationship & Mean & SD & $\mathbf{X}^{\mathbf{2}}$ & df & p value \\
\hline $\begin{array}{l}\text { The CMD place all necessary measures to assist } \\
\text { IAU }\end{array}$ & 3.83 & 0.692 & 96.00 & 4 & 0.000 \\
\hline Duties of IAU are not interfered with by CMD & 3.19 & 0.816 & 4.33 & 4 & 0.115 \\
\hline $\begin{array}{l}\text { Reports made by the IAU are taken serious and } \\
\text { culprit disciplined accordingly by the CMD }\end{array}$ & 4.01 & 0.682 & 14.08 & 4 & 0.001 \\
\hline IAU is independent of the CMD & 3.36 & 0.924 & 22.00 & 4 & 0.000 \\
\hline
\end{tabular}

A p-value of 0.000 for the relationship that CMD place all necessary measures to assist internal audit unit and that internal audit unit is independent of the CMD (table 4). These show that both relationships are statistically significant. The table also shows that indeed, reports made by the internal audit unit are taken serious and culprit are disciplined according to the respondents $(\mathrm{p}=0.001)$.

However, on the issue of whether the duties of the internal audit units are been interfered with by the CMD, the chi-square result has 4.33 and the P-value obtained was 0.115 . This is an indication that IAU duties are been tempered with by the CMD which can affect the integrity of the unit. p- value greater than $0.05(0.115)$ after the chi square test. This reason may cause the internal audit the inability for them to perform their duties effectively and efficiently as the Chief Medical Director may be one of those who the internal audit may have to work on. Interference therefore may not bring out the optimum ability of the internal audit unit to prevent and detect frauds. This observation may however, be in line with that of the descriptive statistics obtained. But in general, according to the table, it could conclude that the relationship between the Chief medical director and the internal audit unit exists.

This finding is in line with findings of Campbell and Lindsay's (1994) and Thomas and Clements (1999) that internal auditors feel mildly positive about the extent of cooperation that exists between their departments and their external auditors in areas of detection and prevention of fraud.

Table 5: Summary of responses and test for significance on the internal audit unit and other departments in the hospital

\begin{tabular}{|l|l|l|l|l|l|}
\hline Relationship & Mean & SD & $\mathbf{X}^{2}$ & df & p value \\
\hline There is cooperation between IAU and various departments & 4.17 & 0.557 & 39.00 & 4 & 0.000 \\
\hline Information is made available to IAU during discharge of duty & 4.00 & 0.411 & 83.00 & 4 & 0.000 \\
\hline There is negative reactions of the auditee towards the auditors & 3.68 & 0.470 & 19.39 & 4 & 0.002 \\
\hline IAU is independent of the CMD & 3.67 & 0.732 & 55.00 & 4 & 0.000 \\
\hline
\end{tabular}

Relationship between the internal audit unit, account and other departments are as shown in table 5. With average values of 4.17, 4.00, 3.68 and 3.67, it indicates that respondents agreed on the average that there is cooperation between internal audit unit and various departments, information is made available to the internal audit unit, there is negative reactions of the auditees towards the auditors and that internal audit is independent of the chief medical director respectively.

The test for significance on the relationship between the internal audit unit and other departments shows that the four relationships show statistical significance. All had p- value of 0.000 except negative reactions of the auditees towards the auditors which had a p- value of 0.002 but still showed a high value of statistical significance. All the results obtained from this table were in agreement with the descriptive statistic obtained from table 7. Based on the findings from this table, we can conclude that there exist a relationship between the internal audit unit and other departments in the hospital. The above finding also correlates with findings of Campbell and Lindsay's (1994) and the KPMG studies (1994, 1995) that internal auditors and external auditors often connive together in the perpetration of fraud rather than detecting it. Feel mildly positive about the extent of cooperation that exists between their departments and their external auditors in areas of detection and prevention of fraud.

Table 6: Summary of responses and test for significance on the possible measures put in place to detect and prevent fraud in Kogi state hospitals

\begin{tabular}{|l|l|l|l|l|l|}
\hline Measures & Mean & SD & $\mathbf{X}^{\mathbf{2}}$ & df & p value \\
\hline Stock taking at least annually & 4.76 & 0.428 & 20.06 & 4 & 0.000 \\
\hline Inspection of goods that were signed for purchase & 4.61 & 0.640 & 44.33 & 4 & 0.000 \\
\hline $\begin{array}{l}\text { Ensuring all vouchers and documents are approved with } \\
\text { auditor's green pen }\end{array}$ & 4.10 & 1.064 & 42.78 & 4 & 0.000 \\
\hline Cross checking all vouchers and pay slips & 4.49 & 0.919 & 81.44 & 4 & 0.000 \\
\hline Going out for market survey & 4.47 & 0.649 & 24.33 & 4 & 0.000 \\
\hline
\end{tabular}


According to the respondents on table 6, stock taking at least annually is one of the measures to put in place in detecting and preventing fraud in the hospital according to the respondents. The average response was 4.76. Similar response was obtained on inspection of goods that were signed for purchase as a means of detecting fraud in hospitals (mean value is 4.61). Respondents also agreed on the average that it is necessary to ensure all vouchers and documents are approved with auditor's green pen. The average value was 4.10. The average value of 4.49 and 4.47 were also obtained for two measures viz: cross checking all vouchers and pay slips and going out for market survey respectively. This also indicates that the respondents also agreed on the average to these two points.

Table 6 also gives the result for the test for significance on the possible measures put in place to detect and prevent fraud in the hospitals. For stock taking at least annually, the p-value obtained was 0.000 which is less than the standard value of 0.05 . When we look at the p-value obtained on the chi square analysis of the inspection of goods that were signed for purchase is a good measure to detect fraud. This means that this measure is a good one to adopt according to the respondents.

Similar results were also obtained on measures like ensuring all vouchers and documents are approved with auditor's green pen; cross checking all vouchers and pay slips and going out for market survey. All of which gave a p-value of 0.000 which affirms that their null hypotheses be rejected.

The results obtained from tables 6 shows that respondents also know their roles as internal auditors in fraud prevention. The first hypothesis can therefore also be rejected and the alternative accepted on this basis.

\section{Conclusion}

Based on the summary of major findings of the study, the following conclusions are drawn. Audit staffs of the hospitals lack the basic rudiments of fraud prevention which is rendering the hospitals more vulnerable to fraud perpetration and resources embezzlement. The audit staffs do not have adequate knowledge guiding their discipline. With the little knowledge available to the audit staff, they still try to halt some fraud incidence the hospitals. This is to say that if better knowledge is acquired, the unit could perform better. CMDs of these hospitals indulge unnecessary in the affairs of the internal audit units. This interference may not be the interest of the unit staff and according to their ethics. Auditors are not deprived of information when needed by their counterparts in other department, though they are not seen as friend because of the nature of their job which they have to expose any fraudulent act regardless of who commits it. Lastly, audit queries issued by the internal audits to the erring staff are not responded to with seriousness.

Based on the findings of this study, the following recommendations are hereby made:

1. Since it has been found that internal audit unit can prevent fraud according to the findings from this study, adequate qualified staffs should be employed by the government into the internal audit units of the hospitals to adequately so that their usefulness in fraud prevention can become much more evident and enhanced.

2. Trainings, seminars and workshops should be organized for the internal auditors so that they can update their knowledge as regards the relevant standards required to prevent and detect fraud in the hospital environment.

3. The relationship between the internal auditors and staffs of other departments should be kept strictly official to disallow such relationship influencing the full discharge of the duty as the auditors.

4. The government and the relevant bodies should establish rules and law which will favor autonomy to the internal audit unit which can prevent interference with the duties of the internal auditors by heads of institutions and the likes.

\section{References}

[1]. Adeniji A. A. (2004), Auditing and Investigation, Lagos: Value Analysis Consult Publisher.

[2]. Birkett, W. P., Barbera, M., Leithhead, B., Lower, M., and Roebuck,P. (1999), Internal Auditing: The Global Landscape, Institute of Internal Auditors' Research Foundation: Florida.

[3]. Campbell, A., and Lindsey, D.H. (1994), Internal auditors and the detection of fraud. Internal Auditing. 9(4): 26-32.

[4]. Connor, P. (1979), Importance of Management Fraud Risk, Amsterdam: Wiley Publication.

[5]. Dandago K. I. (2002), Auditing in Nigeria: A Comprehensive Text, Kano: Adamu Joji publisher.

[6]. DeZoort, T., and Harrison, p., (2008), The Institute of Internal Auditors Research Foundation, An Evaluation of internal Auditor Responsibility for Fraud Detection: Tuscaloosa and Wichita.

[7]. Effiok, A. (2003), Public and Private Enterprise in Nigeria, Calabar: Real press

[8]. KPMG, LLP. (1994), 1993 Fraud Survey, Montvale, NJ: KPMG.

[9]. KPMG, LLP. (1995), 1994 Fraud Survey, Montvale, NJ: KPMG.

[10]. KPMG, LLP. (1999), 1998 Fraud Survey, Montvale, NJ: KPMG.

[11]. KPMG, (2003; 2004), KPMG Fraud survey 2003, Montvale, NJ: KPMG.

[12]. KPMG, ((2006), KPMG Forensic Fraud survey, Australia and New Zealand:KPMG, Australia.

[13]. Thomas, W. C. and Clements, C. E. (2005), The Internal Auditor's Role in the Detection and Prevention of Fraud: A Post-SAS No. 82 Analysis, pp. 33 is a study based on a survey among internal auditors in the US. At http://raw.rutgers.edu/raw/aaa/audit/midyear/02midyear/papers/1-1602\%20Draft.doc. Assessed on 30/01/2012.

[14]. Welch, S. T., Holmes, S.A., and Strawser, R.H. (1996), the inhibiting effect of internal auditors on fraud. Internal Auditing: 12(2), 23-32. 